\title{
Historical track of the development of media technologies and the evolution of advertising forms
}

\author{
$\mathrm{Na} \mathrm{Su}{ }^{1,}$, , Lingling-Luo ${ }^{2, b}$ \\ ${ }^{1} \mathrm{Na} \mathrm{Su}$, Northeastern University, Shenyang City, Liaoning Province, China \\ ${ }^{2}$ Lingling-Luo, Northeastern University, Shenyang City, Liaoning Province, China \\ A 15004059000@126.com, b III_19500619@126.com
}

Keywords: media technologies、 advertising forms、 evolution.

Abstract: Human beings' media technologies has experienced a development course from junior level to senior one. Advertising, as a service industry in the tertiary industry, is the directest and most sensitive to the development ang changes of media technologies in the courses of production and communication. By teasing out the history of the development of global advertising civilization, this paper clearly indicated the dependency and evolution relation between technological motivations and advertising civilization.

From the point of the long river of history development, the advertising morphological evolution is a history for human beings to constantly create and use new media technologies in life, production and communication. Along the history context of media's emergence and development, so far well documented human's advertising evolution and spread is not a process for one mediun to replace another but an interative process for gradual changes.

\section{Ancient advertising patterns - the breakthrough from oral technology to creation transmission}

Ancient "medium" could not be interpreted as medium in its true sense. With the development of human's economic activities, the rudiments of ancient advertising stepped into arenas of history in the simplest forms. Ancient advertising forms were a kind of life advertisements to make a deep and clear declaration to the public. The early symbolic medium period was the initial one in human's advertising culture. Quantities of advertising phenonmena achieved the transition from initial human figures to nonhuman figures, namely material advertisements.

\section{Advertising morphological evolution--- from oral technology to creation transmission}

The advertising communication in the primitive society was in a bud and primary status. The media were mostly the spreaders' body language or natural objects. The goals of the dvertisements were often achieved in the advertising communication forms in which bodies were used as media or carrriers such as certain gestures, verbal languages, tattos, adornments, dance. These body advertising forms had distinct informing and recognition functions, which were regarded as typical primitive advertisements in the bud phase. Human being's tying knots, carving and drawing pictures catalyzed the production of ancient writing, making the development of advertising step on a new stage. In the whole development process for ancient advertising, the transition type of advertising morphological evolution legibly marked different phases of ancient advertising.

From auditory advertisements without media to visual advertisements with media. As there were no media for curing time or delivery space, auditory advertisements dispeared too soon, whose information stayed extremely short, and the transmission range was restricted in the spatial distance. Visual advertisements lied in material carriers, whose information could be kept for a long time. As a result, consumers could receive the information in advertisements asynchronously, which was a great breakthrough in time attribute. As for the oral advertising form, writing made progress to keep pace with the times.

\section{Advertising phenomena promoted by language technology}

Primitive body advertising developed roughly following the structural characteristic evolution sequence from gesture to voice, from language to motion, from motion to posture. With the appearance of languages and then writing, human beings stepped into an age of civilazation. The bud 
of advertising awareness was the origin of advertisements for object exchange. The development of advertising media was shown in the process of gradually extending from human being itself to sorts of tools and objects as the carriers.

Convey simple advertising information with the help of media in nature. To indicate directions or for the defence of enemies, the Hominids drew or carved on natural objects certain simple marks and symbols which contained steady reference or symbolic significance. These marks and symbols were developed into rich religious symbolic signs with tribe's implication and psychology. The quasi physical object tags were objects with cetain characteristics that were attached to other objects or bodies, shown in the world and marked on individuals after being roughly decorated, processed, adjusted, transformed, analysed, referred and fixed. In general, these kinds of object tags had steady and lasting advertising significance.

Bear specific advertising information with manual things. In the ancient society, life tags existed mostly attaching to the activities of stores and pedlars. All kinds of goods in daily life might become media for sound advertising. For instance, utensils such as bowls, calices and basins, and instruments like xiao(a vertical bamboo flute), lyres, se(a twenty-five-stringed instrument), drums and gongs all became tools for transmitting advertising information. Their range of application was restricted in businessmen active areas and parochial markets. As they were used frequently and the masses were accustomed to them, they reflected common people's pleasure, anger, sorrow, joy and aesthetic tastes. Meanwhile, they reflected media users' or businessmen's collective wisdom and the limitations of advertising media's development and use in a low level of productivity.

\section{Advertising cummunication phenomena promoted by metonymy technology.}

In ancient civilization era, to attract customers, promote sales, and implement exchanges, physical display, oral hawking, sign board and ballad came into being. All kinds of primitive advertising forms were flourishing. High-developed feudal civilization and economy promoted handmade primitive advertising forms and advertising communication ways that were suitable to business and technology development at that time. The main characteristic of global advertising communication in this period was the metonymy of matterial objects, display, oral hawking, sound, goods suspension, hanging signs, lanterns, pictures, decorated archways and couplets.

\section{The evolutin of printing technologies}

Printing, one of the four great inventions of ancient China, was developed and perfected by $\mathrm{Pi}$ Sheng into movable-type printing, which was spread to Europe by Mongolians. Printing created condiyions for the wide spread and communication of knowledge. Starting from traditional woodblock printing, to copperplate printing, lithographic printing, ans Collotype technology, it turned to mass machine movable lead printing. Many kinds of printing technologies coexisted in publishing and printing business. Woodblock printing, lithographic printing and movable lead printing coexisted in different phases and had a process of struggling in turns, greatly pushing forward the development of advertising forms as major media technologies.

Printing machines led writing on the way of permanent inheritance. After printing machines were brought in Europe, a full and continous great social transformation was arosen by media technologies in Europe and America. It wa the most profound technology transformation in the western advertising system.

The prosperity and development of advertising forms greatly promoted by printing media technologies

The based technologies of printing media were papermaking and printing. From the advertising form based on information production to printing advertisements based on information replication technology, presswork broke the limitation of human beings' physical distance on spread range. As mass information replication and production realized active wide-range transmission and delivery, the spread range became increasingly wider. The real advertising industry came into being. 
Abundant advertising forms moulded by printing technologies. The arrival of print age led to the standardization of written languages, brought the fierce spread of culture, and widened the time-space coverage in information receiving. With improvement in details for print advertisements, mass media printing advertising gradually appeared in advertising forms. In addition to posters and advertisements in books and newspapers, there were other forms such as leaflets, msnuals, catalogues, booklets, New Year pictures, calendars and printed pictures, which became the main advertising forms together.

The appearance of advertising agents promoted by printing technologies. The progress in media technologies determined the renewal of media, which became the transformative power in the social advertising forms.Newspapers became popular and expanded, manufactures paid for advertisements, media published commercial advertisements, and readers went for purchase after reading advertisements. These promoted a virtuous circle in global advetising industry and meanwhile advertising agencies with the modern characteristics into shape.Advertising industry entered an industry development phase with the main characteristic of professional operation.

Comprehensive spread of advertising communication promoted by printing technologies. The transformation in media technologies made large-scale mass communication come true and accelerated the advertising spread range. Advanced media technologies gradually replaced old ones, which brought down printing costs, shortened the publishing cycles, reduced the media costs, and enlarged the numbers of readers. Media technologies promoted advertising cummunication ideals, which made changes in advertising edit modes and more beautiful in advertising space and more abandant advertising information. With printing technologies as the agent of European social transformation, the transformation in advertising forms was done in a way of destruction before construction.

\section{Modern advertising phase--- the leap in advertising forms caused by audivisual technologies}

\section{Evolution route of advertising forms in audivisual technology phase}

With the establishment of industrial economy forms and segmentation in social division of labor and with the need to information communication and reinforced abilities, the process of mass media began. Radical changes took place in media technologies. Telecommunication equipment like broadcast, TV, films, video were invented and used in advertising. Advertising business gradually stepped into modern audivisual technology era. Advertising business was gradually industrialized and was becoming mature,developing in a high speed as an important part in economy. People were relying on advertising unpreoedentedly.

The invention of telegraph rewrote traditional printing text format rapidly, arising a newspaper revolution in the mass media. As the operation of telegraph was complex, and the information was limited and it did not support two-way communication, people were seeking a more convenient and faster communication ---telephone. Telephone greatly promoted the development of mass media communication. It broke the communication pattern of silent printing text unpreoedentedly, realized two-way communication and broke time and space. After films and broadcast, TV was a widest communication tool with the largest impact and the most coverage. It brought high civilization to human beings and global communication was realized. New development direction for future TV will lie in multifunctional and multimedia technologies. With the intervention of new technologies, the creation activities for composite media advertising art will head for large-scale direction. There was breakthrough progress in hologray, which will make advertising activities going towards the direction of fusing the collective wisdom, teamwork and coordination.

The reversion of printing caused the overall revolution in advertising forms. Reprography has realized the first reversion for media technical evolution in electronic technology level, and regrouped the advertising forms in western world. Telgraph remoulded printing, films, broadcast and TV. The grand change in forms will be bound to change everyone's tendency for vision and perception, and reserve the patterns of preference. Telegraph has accelerated the advertising information flow, helpful 
to creating a new media world in which space is overturned and information can be received in no time.

\section{forms}

The motivation for media technogical reforms in breaking one-dimension advertising

Audivisual technologies needy to wide entertainment extension. The audience's social needs is the motive power of media's production and development. The development of multimedia electronic technologies directly promoted the properity of advertising forms including films, radios, and TV. Sound, light and electronic technologies accelerated the information flow and barriers of time and space were broken thoroughly. The opprtunities and challenges that the electronic media technologies brought to the advertising in western world promoted advertising patterns and reformation with the application of audivisual technologies. Electronic age stemed from telegraph, mechanical age stepped into electronic age, and advertising forms were extended by wide entertainment.

Multiple-dimensional and recreational image advertising forms. Visual communication in multiple-media is a ditinctly important means of information expression. It guides the information receivers' behaviors and thingking, so it is more efficent and profound. The multiple-dimensional and recreational audivisual technological age has provided abundant creative forms for advertising information communication. Interactive designs can attract the audience's multi-sensory like vision, listening, feeling and smelling, interacting with the audience with the help of many equipment such as touch screen,camera and infrared induction, in which the audience enjoy the sense of substitution. Multiple-dimensional advertising forms are coming into the public view.

Fenceless advertising information environment. All kinds of art movements have pushed theatre arts from indoor arenas to streets and traditional art works from galleries and museums to public plazas and sorts of new urban space, which has enchanced the activation of urban advertising virtually. At the same time, the development of outdoor LED electronic screens has provided brand-new space for performance practices in outdoor advertising. The artistic combination light and electricity makes the outdoor advertising's visual impact play incisively and vividly.

For all the advertising media in the world, the introduction of visual means and technologies has made advertisements more entertaining and attractive. With the full display on the advantages of new media like TV and computers, and against the challenges from multiple-dimensional media, the long history of over 500 years ruled by tyrant printing machines will be turned a new leaf.

\section{Contemporary advertising forms--- the leap of Internet digital media intergration}

In the end of the 20th century, human society experienced the transformation from atomic age to digital age, which accelerated the birth of computer network media technoloies. With the push of a strong power high-tech, the development of advertising forms in network technology era has taken shape, showing its evolution as follows.

\section{The evolution process of network media technoloies}

The development of network media technoloies has experienced Web1.0 Age in which browse information is given priority to, Web2.0 Age with interactive share and Web3.0 Age with the aggregation of platforms. With the appearance of smartphones, the pattern and status started by the Inernet can not block the pace of the development of the mobile Internet platform. The mobile Internet platform used the mobile phone as the terminal, intergated with the functions of newspapers, broadcast, TV, traditional Internet, and provided new social contact and advertising madia platforms. Search engines have been the focus of advertising forms in the media intergation state, and will fully permeate in all advertising forms, realizing the precision marketing communication in advertising. It is a grand leap in advertising activities, changing the advertising forms profoudly.

\section{The advertising industry pattern with all media convergence}

Any new medium has an evolution process and opens a door to perception and new fields of activities for human beings. In the future, new media will jointly develop with taditional media in the 
course of fusion, intergration,interaction and promotion. The formation in media intergration and changes in advertising forms will permeate in every field like production, consumption and trade, the advertising forms that go through the whole media industry will change correspondingly, and the related advertisers, media, audience and comsumers will step into a new advertising age.

The intergration of advertising media between network technologies and audivisual technologies. The intergration of digital technologies, computer network technologies and mobile communication technoloies have constituted the technology platform for the development of new media and provided the basis for the intergration of advertising media. The network has characteristics like real-time interaction and globlization. In the performance forms, it has surpassed the limitation of a single medium, has intergrated media effects including texts, pictures, videos, sounds and cartoons, and has a platform of extremely strong interactive functions. The state of intergration has obscured the boundary among the media.

The full permeation of new gigital media. In electronic and digital information environment, the conception of medium is totally different. Language, image, and even sound can be stored in invisible electronis space or a digital byte stream, and every data has unlimited changes, remoulds and flows. As a wide conception, new gigital medium refers to a communication form that provides information and entertainment services to its users with terminals including computers, mobile phones and digital TV in the channels like the Internet, broadband LAN,wireless communication network, and satellites by the the means of digital technologies, network technologies. Led by information science and digital technologies, and based on the mass communication theory, it is a pattern of manifestation of the high intergration between science and culture in which advertising information communication technologies are applied to culture, arts, entertainment, business, education and management.

The gradual manifestation of media intergration. Media intergration refers to the evolution process in which contents, network and terminals are intergrated to make up a media form in the background of digital technologies and network technologies in the guidance of the information consumption terminals'needs, forming a pattern of "Big media"industry. The evolution for conceptions and forms in media advertising goes side by side with the development of technologies. Media advertising can be considered as an advertising revolution in conceptions, in forms of arts, and in ways of creation. It not only is shown in the intergration and creativity on technologies and ideals, bu also has changed human beings' life styles. The intergration of media is not to simply wipe out all kinds of existing media, but to create a new medium according to information communication rules and with a stronger vitality. The alternation between new and old media is a gradual but not fierce evolution revolution. When a new medium form appears, the old ones will not die out.Instead, they will evolute and adapt to new conditions, which is called "co-evolution".

\section{Conclusions}

Reviewing the history of the advertising evolution and development of media technologies, with the evolution of media technologies as the main line, the evolution for conceptions and forms in media advertising goes side by side with the development of technologies. Advertising, as a service industry in the tertiary industry, is the directest and most sensitive to the development ang changes of media technologies in the courses of production and communication. On the development outline of media technologies in the historic course from ancient advertising ingformation carriers to today's digital new medium, advertising forms were always modified by technologies in the case of normal use of media technologies. In reverse, advertising forms were seeking new means to modify their own media technologies.In the contradictory relation, advertising forms were resticted and controlled by media technologies and promoted into new phases.

We can clearly find out the dependency relation between technological motivations and advertising civilization, which not only indicate the evolution track but also is a response in modern advertising field to the rule thatmedia technologies pushed civilization. 


\section{References}

[1] The history of Chinese advertising. ChenZhao Chen. Beijing. Higher education press [M]. 2005:10-12.

[2] Review of journalism and communication. Wenjie Sun [J]. 2012, 3.

[3] The world civilization Shian Li . Beijing: China development press [M]. 2000.

[4] Heilongjiang science and technology information. Yun-ling liu [J]. 2009, 34

[5] Journal of wuhan university (philosophy and social science edition). Maojun Zhou . [J]. Volume 58. 136 